\title{
Prevalence of helminthes in small ruminants in Tarai region of Uttarakhand
}

\author{
Kripali Pant, M.K.S. Rajput, J itendra Kumar, Shivani Sahu, Vandna, Rajkumari \\ and Pritee Gangwar \\ Department of Epidemiology and Preventive Medicine \\ College of Veterinary and Animal Sciences, \\ G.B. Pant University of Agriculture and Technology, Pantnagar, India.
}

\begin{abstract}
Out of 150 small ruminants examined from villages near Pantnagar and organized farms, among them 144 animals were found positive for mixed parasitic infection, including Haemonchus sp, Paramphistomum sp, Trichuris sp. and Moniezia sp. Overall prevalence was found $96.00 \%$ in which animals from villages has more prevalence $(96.15 \%)$ than organized farm $(96.00 \%)$ but organized farms has more prevalence of Haemonchus sp $(95.00 \%)$ than animals of villages (76.92\%), overall Paramphistomum sp was found $36.00 \%$ while Trichuris $s p$ and Moniezia $s p$ revealed $14.00 \%$ and $12.00 \%$ prevalence, respectively.
\end{abstract}

Keywords: Prevalence, Helminth, Ruminant,

\section{I ntroduction}

The small ruminants like sheep and goats has enormous potential to boost economy of our country and they play a major source of income especially to marginal farmers and landless labor of our country but various helminthes diseases are responsible for causing heavy losses due to reduced production, morbidity and mortality in animals. In spite of significant production losses, which may run into millions of rupees (Shah and Chaudhry, 1995) the problem is neglected due to its chronic and insidious nature (Sanyal, 1998). Epidemiological pattern of the parasitic diseases in the different areas of the country would provide a basis for evolving strategic and tactical control of these disease in this continuation several studies has been conducted to find out its prevalence of GIT parasites in small ruminates at different parts of our country (Pathak et al., 2008). Taking this background the present study was conducted to find out prevalence in tarai region of Uttarakhand.

\section{Materials and Methods}

Total 150 fecal samples (130 samples from villages near Pantnagar where 3-5 animals are kept as backyards practice and 20 samples from organized farm at Pantnagar) were collected directly from rectum during months of September 2008 to October 2008 and brought to laboratory in clean sterilized plastic vials. All samples were examined first by direct smear method and negativity was confirmed by concentration method using saturated salt solution as per method described by (Soulsby, 1982).

\section{Results and Discussion}

The overall prevalence of GIT parasite was found $96.00 \%$, in which animals from villages revealed $96.15 \%$ that is comparatively higher than prevalence in organized farms $(90.00 \%)$, it may be due to regular use of anthelmintic drugs in organized farms. In villages Haemonchus sp. showed its higher prevalence as $76.92 \%$ followed by Paramphistomum sp and Trichuris sp. as $38.46 \%$ and $15.38 \%$ respectively, while Moniezia sp. revealed its lowest prevalence as $13.07 \%$. In organized farm the highest prevalence was noticed for Haemonchus sp as $95.00 \%$ which is comparatively higher than prevalence of villages, it may be due to continues use of anthelmintic drugs that may lead to anthelmintic resistant in Haemonchus sp. (Uppal, et al., 1992). Animals from organized farms showed prevalence of Paramphistomum sp as $20.00 \%$ while for Trichuris sp. and Moniezia sp. were $5.00 \%$ each that is lower than village's prevalence it may be due to managemental practice followed in organized farms.

\section{Acknowledgement}

Authors are thankful to Dean, College of Veterinary and Animal Sciences and Director, Experiment Station, G.B. Pant University of Agriculture and Technology, Pantnagar, for providing the facilities required for conducting research work. 
Prevalence of helminthes in small ruminants in Tarai region of Uttarakhand

\section{References}

1. Pathak, A.K. and Pal, S. (2008): Seasonal prevalence of gastrointestinal parasites in goats from Durg district of Chhattisgarh. Veterinary world. 5: 136-137.

2. Sanyal, P.K. (1998): Integrated gastrointestinal parasite management in dairy animals in Gujarat by self medication. J. Vet. Parasito. 12: 17-20.

3. Shan, H.L. and Chaudhry, R.K. (1995): Parasitism in dairy animals in India: Present status and its impact. In: Proceedings of the workshop on control strategy against gastrointestinal parasites in dairy animals in India using medicated urea molasses blocks. (NDDB, Anand, India) 1-5.

4. Soulsby, EJL. (1982): Helminthes, arthropods and protozoa of domesticated animals. VII edn. Baillere Tindall, Landon, p. 766.

5. Uppal R. P., Yadav C. L. ; Godara P., Rana Z. S.(1992) Multiple anthelmintic resistance in a field strain of Haemonchus contortus in goats. Veterinary Research Communications. 16. 195-198. 